\title{
A Weibull Distribution: Flow and Heat Transfer of Nanofluids Containing Carbon Nanotubes with Radiation and Velocity Slip Effects
}

\author{
Izamarlina Asshaari, ${ }^{1}$ Alias Jedi $\mathbb{D}^{2},{ }^{2}$ and Kafi Dano Pati ${ }^{3}$ \\ ${ }^{1}$ Department of Engineering Education, Faculty of Engineering and Built Environment, Universiti Kebangsaan Malaysia, \\ 43600 UKM, Bangi, Selangor, Malaysia \\ ${ }^{2}$ Department of Mechanical and Manufacturing Engineering, Faculty of Engineering and Built Environment, \\ Universiti Kebangsaan Malaysia, 43600 UKM, Bangi, Selangor, Malaysia \\ ${ }^{3}$ University of Duhok, College of Science, Department of Computer Sciences, Zakho Street 38, 1006 AJ Kurdistan Region, \\ Duhok, Iraq \\ Correspondence should be addressed to Alias Jedi; aliasjedi@ukm.edu.my
}

Received 19 February 2020; Revised 14 May 2020; Accepted 30 May 2020; Published 7 July 2020

Academic Editor: Parviz Ghadimi

Copyright (c) 2020 Izamarlina Asshaari et al. This is an open access article distributed under the Creative Commons Attribution License, which permits unrestricted use, distribution, and reproduction in any medium, provided the original work is properly cited.

\begin{abstract}
In this study, the Tiwari and Das model is numerically studied, in case of a moving plate containing both single-walled and multiwalled carbon nanotubes (SWCNTs and MWCNTs, respectively), in the presence of thermal radiation and the slip effect. Employing the similarity transformation, a set of 2nd-order partial differential equations (which are used to model the flow and heat transfer) are solved numerically using the boundary value problem with 4th-order accuracy (BVP4C) method. The effects of related parameters, such as the volume fraction of nanoparticles, moving, slip, and radiation parameter on the heat transfer performance are analysed and discussed. Results indicate that a unique solution was placed when the plate travels in assisting flow conditions. Additionally, as the nanoparticle volume fraction $(\varphi)$ rises at $\varphi=0.2$, the skin friction and heat transfer rate decrease. It is also observed that when the slip parameter $(\beta)$ increases at $\beta=0.4$, the skin friction decreases, whereas the heat transfer rate increases. Meanwhile, the heat transfer rate decreases when the thermal radiation $\left(N_{R}\right)$ increases to 0.7. Moreover, it is found that the SWCNTs are more efficient when the skin friction coefficient and the Nusselt number are considered. It is found that the Weibull distribution is more suitable in fitting the skin friction data.
\end{abstract}

\section{Introduction}

Originally discovered in 1995, nanofluids are a class of fluids that have been attracting significant attention of researchers in various fields. Owing to their advantages, nanofluids have been implemented in various industrial sectors, such as energy and biomedical fields. Choi and Eastman [1] reported that the thermal conductivity of nanofluids can be enhanced by dispersing nanosized particles in the fluid. Moreover, it was discovered that the flow of the base fluid improved by suspending nanoparticles in it [2]. Alwaeli et al. [3] also reported that the addition of alumina and carbon black nanoparticles improved the cooling effect on the solar panels. Meanwhile, carbon nanotubes (CNTs) have become one of the most effective materials, owing to their ability to enhance the thermal characteristics of the fluid, high electrical conductivity, unique optical transmission, and high tensile strength. They can also increase the entropy generation [4]. CNTs are rolled-up graphene sheets arranged in a cylindrical shape. They are of two types: single-walled (SWCNTs) and multiwalled (MWCNTs) [5]. It was observed that the boundary layer separation could be delayed if suction effects on the CNTs' nanoparticle volume fraction are provided [6]. According to Naganthran et al. [7] and Ahmad et al. [8], CNTs have higher thermal conductivity. When dispersed in the base fluid, they can accelerate the rate 
of the heat transfer and subsequently increase the base fluid's thermal conductivity. Using Buongiorno's concept, Khan et al. [9] analysed the effects of the Brownian motion and thermophoresis on the CNTs' flow, using Xue's model. Anuar et al. [10] reported the enhanced performance of CNTs, owing to the existence of the velocity slip in boundary conditions.

Nanoparticles exhibit very unique physical and mechanical properties [11]. Graphene nanoparticles, for example, are used in many applications, especially in nanotechnology [12] and more widely in cooling technology $[13,14]$. As such, the study of rheological characteristics of the hybrid nanofluids is of considerable importance in order to determine the effects of two or more nanoparticles in a base fluid $[15,16]$. The important outcome of such a hybrid nanoparticle is to enhance the thermal properties of nanofluids in heat transfer applications [17-20]. There are many widely used methods to enhance heat transfer. For instance, nanofluids are used to increase the heat transfer rate $[21,22]$. Additionally, suitable changes in the geometrical conditions, cross-sectional area, and composition of microchannels $[23,24]$ can also significantly improve the heat transfer performance.

In previously reported studies, the researchers focused only on studying the boundary layer flow of nanofluids, without considering the slip effect. As a result, Bhattacharyya et al. [25] explored the presence of slip effect and found that, as the value of the velocity slip parameter increased, it resulted in a decrease of the boundary layer thickness. Using this concept, Bachok at al. [26] applied this study to a moving plate, using dispersed copper nanoparticles in a base fluid. Later, Imtiaz et al. [27] analysed the effects of CNTs by employing the thermal radiation effect in the modelling systems and discovered that single-wall CNTs offer a larger heat transfer rate. Many intriguing properties of nanofluids have been discussed in the literature presented here. Recently, as scientists are showing significant interest in heat transfer properties, the utilization of nanofluids in real-life situations, in this aspect, seems promising. To achieve this, fundamental research in the mathematical aspect of the thermal conductivity of nanofluids is needed in order to understand the mechanisms that can change the nanofluid behaviour. Therefore, the objective of this study is to investigate and highlight the effects of thermal radiation and slip parameter of SWCNTs and MWCNTs in the case of a moving plate. This is performed by employing a theoretical mathematical model, previously introduced by Tiwari and Das [28]. Their model presented the effects of nanoparticle volume fraction in influencing the viscosity of the nanofluid.

\section{Materials and Methods}

2.1. Governing Equations. Consider a steady, two-dimensional horizontal moving plate, which is placed in a nanofluid containing SWCNTs and MWCNTs. The plate has a constant velocity $U_{w}$. The temperature of the wall, $T_{w}$, is expected to remain uniform, whereas the temperature, $\mathrm{T}_{\infty}$, of the ambient fluid is assumed constant. A schematic of the model is shown in Figure 1. Taking into account the thermal

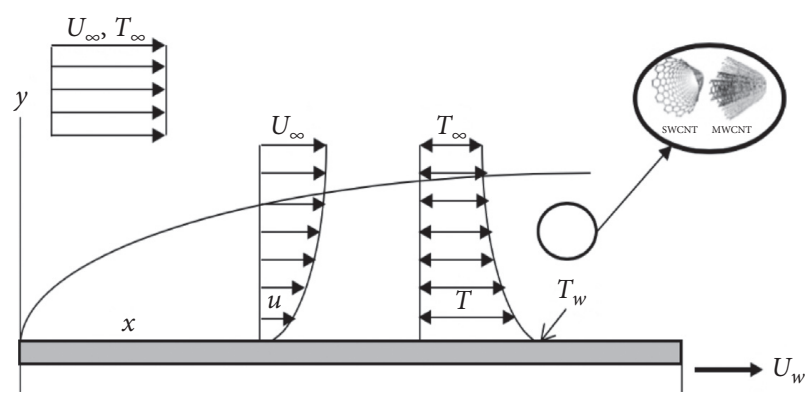

Figure 1: Flow configuration of the physical phenomenon.

radiation effect, the following equations can be written (as indicated in $[20,21])$ :

$$
\begin{gathered}
\frac{\partial u}{\partial x}+\frac{\partial v}{\partial y}=0 \\
u \frac{\partial u}{\partial x}+v \frac{\partial u}{\partial y}=\frac{\mu_{\mathrm{nf}}}{\rho_{\mathrm{nf}}} \frac{\partial^{2} u}{\partial y^{2}} \\
u \frac{\partial T}{\partial x}+v \frac{\partial T}{\partial y}=\alpha_{\mathrm{nf}} \frac{\partial^{2} T}{\partial y^{2}}-\frac{1}{\left(\rho C_{p}\right)_{\mathrm{nf}}} \frac{\partial q_{r}}{\partial y} .
\end{gathered}
$$

Solving equations (1)-(3), the following conditions are derived:

$$
\begin{aligned}
& u=U_{w}+\xi_{1}\left(\frac{\partial u}{\partial y}\right), v=0, T=T_{w} \text { at } y=0, \\
& u \longrightarrow U_{\infty}, T \longrightarrow T_{\infty} \text { as } y \longrightarrow \infty,
\end{aligned}
$$

where $u$ and $v$ are the velocity elements (in $x$ and $y$ directions, respectively), $T$ is the temperature in the boundary layer (in Kelvin), $q_{r}$ is the radiative heat flux, $\mu$ is the viscosity, and $\rho$ and $\alpha$ are the density and thermal diffusivity of the nanofluid. Here, $\xi_{1}$ denotes the slip factor and is defined as $\xi_{1}=\xi \sqrt{\operatorname{Re}_{w}+\operatorname{Re}_{\infty}}$, where $\xi$ is the primary length and $\operatorname{Re}_{w}$ and $\operatorname{Re}_{\infty}$ are the Reynolds numbers.

It is important to have a basic understanding about the thermophysical properties of nanofluids, such as thermal diffusivity, density, dynamic viscosity, heat capacity, and thermal conductivity, before we develop a thermal system. For example, thermal conductivity is an important factor in determining the heat transfer effectiveness. Moreover, the dynamic viscosity indicates that the resistance of the fluid directly affects the pressure and decreases it, for example, in pumping power (PP) systems. Meanwhile, the effectiveness of the working fluid is determined by the heat capacity, which can be inferred from the fact how the generated heat moves away from the heat source, in the fluid. Table 1 lists the thermal diffusivity, density, dynamic viscosity, heat capacity, and thermal conductivity of nanofluids. The relations given in the second column indicate that these parameters are suitable and quite important to determine the effect of CNTs on the flow and heat transfer of the system.

Table 2 lists the physical properties of water (base fluid), SWCNTs, and MWCNTs. 
TABle 1: Parameters defined in the work [29].

\begin{tabular}{|c|c|}
\hline Parameters & Governing equations \\
\hline $\begin{array}{l}\text { Thermal } \\
\text { diffusivity }\end{array}$ & $\begin{array}{c}\alpha_{\mathrm{nf}}=\left(k_{\mathrm{nf}} /\left(\rho C_{p}\right)_{\mathrm{nf}}\right) \text {, where } \\
k_{\mathrm{nf}}=\text { thermal conductivity of nanofluids } \\
\left(\rho C_{p}\right)_{\mathrm{nf}}=\text { heat capacity of nanofluids }\end{array}$ \\
\hline Density & $\begin{array}{c}\rho_{\mathrm{nf}}=(1-\varphi) \rho_{f}+\varphi \rho_{\mathrm{CNT}} \text {, where } \\
\varphi=\text { nanoparticle volume fraction } \\
\rho_{\mathrm{f}}=\text { density of the fluid } \\
\rho_{\mathrm{CNT}}=\text { density of carbon nanotubes }\end{array}$ \\
\hline $\begin{array}{l}\text { Dynamic } \\
\text { viscosity }\end{array}$ & $\begin{array}{c}\mu_{\mathrm{nf}}=\left(\mu_{f} /(1-\varphi)^{2.5}\right) \text {, where } \\
\mu_{\mathrm{f}}=\text { dynamic viscosity of the fluid } \\
(\rho C \text { ) }\end{array}$ \\
\hline Heat capacity & $\begin{array}{c}\left(\rho C_{p}\right)_{\mathrm{f}}=\text { heat capacity of the fluid } \\
\left(\rho C_{p}\right)_{\mathrm{CNT}}=\text { heat capacity of carbon nanotubes }\end{array}$ \\
\hline $\begin{array}{l}\text { Thermal } \\
\text { conductivity }\end{array}$ & $\begin{array}{c}\left(k_{\mathrm{nf}} / k_{\mathrm{f}}\right)=\left(\left(1-\varphi+2 \varphi\left(k_{\mathrm{CNT}} /\left(k_{\mathrm{CNT}}-k_{\mathrm{f}}\right)\right) \ln \left(\left(k_{\mathrm{CNT}}+k_{\mathrm{f}}\right) / 2 k_{\mathrm{f}}\right)\right) /\left(1-\varphi+2 \varphi\left(k_{\mathrm{f}} /\left(k_{\mathrm{CNT}}-k_{\mathrm{f}}\right)\right) \ln \left(\left(k_{\mathrm{CNT}}+k_{\mathrm{f}}\right) / 2 k_{\mathrm{f}}\right)\right)\right), \\
\text { where } \\
k_{\mathrm{nf}}=\text { thermal conductivity of nanofluids } \\
k_{\mathrm{f}}=\text { thermal conductivity of the fluid } \\
k_{\mathrm{CNT}}=\text { thermal conductivity of carbon nanotubes }\end{array}$ \\
\hline
\end{tabular}

TABLE 2: The physical properties of fluids and CNTs [30].

\begin{tabular}{lccc}
\hline \multirow{2}{*}{ Physical properties } & Base fluid & \multicolumn{2}{c}{ Carbon nanotubes } \\
& Water & SWCNT & MWCNT \\
\hline$\rho\left(\mathrm{kg} \mathrm{m}^{-3}\right)$ & 997 & 2600 & 1600 \\
$C_{p}\left(\mathrm{~J} \mathrm{~kg}^{-1} K^{-1}\right)$ & 4179 & 425 & 796 \\
$k\left(\mathrm{~W} \mathrm{~m} \mathrm{~K}^{-1}\right)$ & 0.613 & 6600 & 3000 \\
$\mu_{\mathrm{f}}\left(\times 10^{-3} \mathrm{~kg} / \mathrm{m} . \mathrm{s}\right)$ & 1.781 & & \\
\hline
\end{tabular}

Applying the Rosseland approximation [24, 25], the thermal radiation is expressed as

$$
q_{\mathrm{r}}=-\frac{4 \sigma^{*}}{3 k^{*}} \frac{\partial T^{4}}{\partial y},
$$

with $\sigma^{*}$ and $k^{*}$ are Stefan-Boltzmann's and average absorption's coefficients, respectively.

Omitting the higher order, $T$ can be expressed as

$$
T^{4} \approx 4 T_{\infty}^{3} T-3 T_{\infty}^{4} .
$$

Equation (6) is differentiated over $T$, and then resubstitute the results in equation (5); therefore, equation (3) now becomes

$$
u \frac{\partial T}{\partial x}+v \frac{\partial T}{\partial y}=\left(\alpha_{\mathrm{nf}}+\frac{16 \sigma^{*}}{3 k^{*}} \frac{T_{\infty}^{3}}{\left(\rho C_{p}\right)_{\mathrm{nf}}}\right) \frac{\partial^{2} T}{\partial y^{2}} .
$$

To solve the set of partial equations (1)-(8) and taking into account the equations in Table 1 , we applied the similarity transformation [31], which is given by the following equation:

$$
\begin{aligned}
\eta & =\sqrt{\left(\frac{U}{v_{\mathrm{f}} x}\right)} y, \\
\psi & =\sqrt{v_{\mathrm{f}} x U} f(\eta), \\
\theta(\eta) & =\frac{T-T_{\infty}}{T_{w}-T_{\infty}} .
\end{aligned}
$$

Here, $U$ represents the composite velocity $U=U_{w}+U_{\infty}$, $\theta$ the dimensionless temperature, and $\psi$ is the stream function. Here, the terms $u$ and $v$ are defined as $u=(\partial \psi / \partial y)$ and $v=-(\partial \psi / \partial x)$, which satisfy continuity equation (1). This leads us to

$$
\begin{gathered}
\frac{1}{(1-\varphi)^{2.5}\left(\left(1-\varphi+\varphi \rho_{\mathrm{CNT}}\right) / \rho_{f}\right)} f^{\prime \prime \prime}+\frac{1}{2} f f^{\prime \prime}=0, \\
\frac{1}{\operatorname{Pr}} \frac{k_{n f} / k_{f}}{(1-\varphi)+\left(\left(\varphi\left(\rho C_{p}\right)_{\mathrm{CNT}}\right) /\left(\rho C_{p}\right)_{f}\right)}\left(1+\frac{4}{3} N_{R}\right) \theta^{\prime \prime}+\frac{1}{2} f \theta^{\prime}=0,
\end{gathered}
$$

with the radiation parameter $N_{R}=\left(\left(4 \sigma^{*} T_{\infty}^{3}\right) /\left(k^{*} k\right)\right)$ and Prandtl number $\operatorname{Pr}=\left(v_{f} / \alpha_{f}\right)$. In accordance with equations (9) and (10), converted equation (4) can be represented as

$$
\begin{aligned}
& f(0)=0, \\
& f^{\prime}(0)=\gamma+\beta f^{\prime \prime}(0), \quad \theta(0)=1, \\
& f^{\prime}(\eta) \longrightarrow 1-\gamma, \quad \theta(\eta) \longrightarrow 0 \text { as } \eta \longrightarrow \infty,
\end{aligned}
$$

where the velocity ratio parameters, $\gamma$ and $\beta$, are expressed as

$$
\begin{aligned}
& \gamma=\frac{U_{w}}{U}, \\
& \beta=\xi \frac{U}{v_{\mathrm{f}}} .
\end{aligned}
$$

It is necessary to identify the skin friction coefficient $C_{f}$ and the local Nusselt number $N u_{x}$, which are expressed as

$$
\begin{aligned}
C_{\mathrm{f}} & =\frac{\tau_{w}}{\rho_{\mathrm{f}} U^{2}}, \\
N u_{x} & =\frac{x q_{w}}{k_{\mathrm{f}}\left(T_{w}-T_{\infty}\right)},
\end{aligned}
$$

where $\tau_{w}$ and $q_{w}$ are defined as 


$$
\begin{aligned}
& \tau_{w}=\mu_{\mathrm{nf}}\left(\frac{\partial u}{\partial y}\right)_{y=0}, \\
& q_{w}=-k_{\mathrm{nf}}\left(\frac{\partial T}{\partial y}\right)_{y=0}+\left(q_{r}\right)_{y=0} .
\end{aligned}
$$

To derive an expression for equations (13) and (14), equation (8) is used. So, we can write

$$
\begin{gathered}
C_{\mathrm{f}} \operatorname{Re}_{x}^{(1 / 2)}=\frac{1}{(1-\varphi)^{2.5}} f^{\prime \prime}(0), \\
N u_{x} \operatorname{Re}_{x}^{-1 / 2}=-\left(\frac{k_{\mathrm{nf}}}{k_{\mathrm{f}}}+\frac{4}{3} N_{\mathrm{R}}\right) \theta^{\prime}(0),
\end{gathered}
$$

where $\operatorname{Re}_{x}=\left(U x / \nu_{\mathrm{f}}\right)$ is the local Reynolds number.

2.2. Anderson-Darling Test Statistic. The data for the reduced skin friction were further analysed using the Anderson-Darling (AD) statistic. The goodness of fit is determined to verify which distribution in the skin friction data fits well. The $\mathrm{AD}$ test was selected over other tests because of two reasons: (1) the AD test is one of the best goodness-of-fit tests for a small size of the sample, and (2) the AD test is, most often, used in practice. To check which distribution in the data would follow, we need to apply the hypothesis tests that will be discussed later in this paper. The null hypothesis states that the data would follow a specific population as stated in Table 3 . However, the alternative hypothesis states that the data would not follow a specific population.

First, the test statistic $\mathrm{AD}^{*}$ must be computed based on $\mathrm{AD}$, but to conclude which best fits the data, the $\mathrm{AD}^{*}$ test statistic must be significantly lower than the others. Hence, we conclude that the skin friction data were drawn from a specific population. The $\mathrm{AD}^{*}$ test statistic is illustrated in Table 4, and the formula to compute the $\mathrm{AD}$ is given as follows:

$$
\mathrm{AD}=-n-\frac{1}{n} \sum_{i=1}^{n}\left[(2 i-1)\left[\ln G\left(x_{i}\right)+\ln \left(1-G\left(x_{n-i+1}\right)\right)\right]\right]
$$

where $n$ is the sample size, $i$ runs from 1 to $n$ (calculated when the skin friction data are sorted in the ascending order), and $F\left(x_{i}\right)$ is a CDF for the specified distribution function.

\section{Results and Discussion}

The obtained results are analysed in order to demonstrate the CNTs' flow in the influences of $N_{R}$ and $\beta$. With the help of the bvp4c solver in software MATLAB, the system of nonlinear ordinary equations (9) and (10) and conditions given in equation (11) are numerically solved. The solver bvp4c was programmed with a finite difference code that implements the 3-stage Lobatto IIIa formula. This effective solver required the users to have a set of initial guesses with a combination of the boundary layer thickness. Results are obtained when the boundary conditions are asymptotically fulfilled, and no errors are produced in MATLAB. The use of bvp4c codes solved the transformed momentum and energy equations (9) and (10), respectively, and boundary conditions given in equation (11), thus validating the numerical result. The obtained values for the present results and the data obtained from previously reported studies $[10,32]$ are included in Table 5 for comparison. As evident, the present result and the data in the literature are found to be in agreement.

Figures 2 and 3 elucidate the water-SWCNTs' variations, for different values of $\varphi$, from 0 to 0.2 , when $\beta=0.2$ and $N_{R}=0.1$. As it is seen, the dual solutions occur when the plate shifts to opposite directions $\left(\gamma_{c}<\gamma<0\right)$, while an exact solution occurs when the plate moves in assisting flow conditions $(\gamma \geq 0)$. However, no solution exists when $\gamma<\gamma_{c}$. As seen, the increase in $\varphi$ results in decreased $f^{\prime \prime}(0)$ values. In Figure 2, it is evident that the effect of slip parameter and thermal radiation as well as CNTs added to the nanofluid made it more viscous. Hence, increasing $\varphi$ will increase the fluid viscosity, thereby increasing the fluid's resistance to flow. Figure 3 indicates that the heat transfer rate decreases with increasing aided volume fraction of nanoparticles. The effect of radiation parameter transports heat to functional flow, and hence, the squeezed nanofluid flow temperature decreases.

The variation of $C_{f} \operatorname{Re}_{x}^{1 / 2}$ with different ranges of $\varphi$ and $\beta$ is presented in Figures 4 and 5 as the plate travels in assisting flow. As highlighted in Figure 4, if the value of $\beta$ increased in both SWCNTs and MWCNTs, the skin friction coefficient $C_{f} \operatorname{Re}_{x}^{1 / 2}$ begins to depreciate. However, in Figure 5, Nu $\operatorname{Re}_{x}^{-1 / 2}$ increases with the increase of $\varphi$. As seen, larger values of ${ }^{x}{ }_{f} \mathrm{Re}_{x}^{1 / 2}$ and $N u_{x} \operatorname{Re}_{x}^{-1 / 2}$ are seen by SWCNTs due to their larger density and thermal conductivity. These are illustrated in Figures 4 and 5. High values of heat transfer rate and fluid friction factor for SWCNTs (compared with MWCNTs) are due to thermal boundary resistance between the CNT and the surrounding fluid. SWCNTs are highly hydrophobic because the particles are bounded together due to higher van der Waals force of attraction.

The SWCNTs' flow and heat transfer are further verified by studying the effects of difference in ranges of $\varphi$ on the velocity and temperature profiles. Figures 6 and 7 graphically illustrate the convergence series solution of the velocity and temperature profiles. From the figures, it is noted that these profiles asymptotically suffice the converted conditions in equation (11). The dual solutions can also be spotted from these figures. Moreover, the exact solutions have a boundary layer thickness thinner than that of the dual solutions. It also indicates that $f^{\prime}$ is a decreasing function of $\varphi$, owing to an increase in $\varphi$. However, in Figure 7, with the presence of $N_{R}=0.1$ and $\beta=0.2$, the thermal boundary layer thickness increases, which would decelerate the heat transfer.

Figures 8 and 9 portray the effect of $\beta$ on the velocity and temperature profiles. These figures indicate that, as the value of $\beta$ increases, the momentum thickness and thermal boundary layer thickness decrease. The influence of various values of thermal radiation on the temperature profile for water-based SWCNTs is also presented in Figure 10. It can 
Table 3: Distribution test for $f^{\prime \prime}(0)$.

\begin{tabular}{lr}
\hline Distribution & Cumulative distribution function $(\mathrm{CDF}), G\left(x_{i}\right)$ \\
\hline $\begin{array}{l}\text { Weibull } \\
\text { Exponential }\end{array}$ & $G\left(x_{i}\right)=1-e^{-\left(x_{i} / \delta\right)^{\beta}}$, where $x_{i}, \delta$, and $\beta$ stand for the skin friction data, scale, and shape parameters, respectively. \\
Gamma & $\begin{array}{r}G\left(x_{i}\right)=1-e^{\left(-\theta x_{i}\right)}, \text { where } x_{i} \text { and } \theta \text { stand for the skin friction data and the scale parameter, respectively. } \\
\left.\left(\gamma_{\text {Stac }}\left(\delta,\left(x_{i} / \beta\right)\right)\right) /(\Gamma(\delta))\right) \text {, where } \Gamma(\delta) \text { is the gamma function, } x_{i}, \delta \text {, and } \beta \text { stand for the skin friction, scale, } \\
\text { and shape parameters, respectively. } \gamma_{\text {Stac }}\left(\delta,\left(x_{i} / \beta\right)\right) \text { is the lower incomplete gamma function. }\end{array}$ \\
\hline
\end{tabular}

TABLE 4: Anderson-Darling test statistic.

\begin{tabular}{lc}
\hline Distribution & $\mathrm{AD}^{*}$ value \\
\hline Weibull & $\mathrm{AD}(1+(0.2 / \sqrt{n}))$ \\
Exponential & $\mathrm{AD}(1+(0.6 / \sqrt{n}))$ \\
Gamma & $\mathrm{AD}(1+(0.6 / n))$ \\
\hline
\end{tabular}

TABLe 5: Data of $f^{\prime}(0)$ for water-SWCNT with the absence of $N_{R}$ and $\beta$.

\begin{tabular}{|c|c|c|c|c|c|c|c|}
\hline \multirow[t]{2}{*}{$\Phi$} & \multirow[t]{2}{*}{$\Lambda$} & \multicolumn{2}{|c|}{$\begin{array}{c}\text { Bachok } \\
\text { et al. [32] }\end{array}$} & \multicolumn{2}{|c|}{ Anuar et al. [10] } & \multicolumn{2}{|c|}{ Present result } \\
\hline & & First & Second & First & Second & First & Second \\
\hline \multirow{6}{*}{0} & -0.3 & 0.4339 & 0.0367 & 0.4339 & 0.0367 & 0.4339 & 0.0367 \\
\hline & -0.2 & 0.4124 & 0.0114 & 0.4124 & 0.0114 & 0.4124 & 0.0114 \\
\hline & -0.1 & 0.3774 & 0.001 & 0.3774 & 0.0011 & 0.3774 & 0.0011 \\
\hline & 0 & 0.3321 & & 0.3321 & & 0.3321 & \\
\hline & 0.5 & 0 & & 0 & & 0.0000 & \\
\hline & 1 & 0.4438 & & 0.4438 & & -0.4437 & \\
\hline \multirow{6}{*}{0.1} & -0.3 & & & 0.4098 & 0.0345 & 0.4098 & 0.0347 \\
\hline & -0.2 & & & 0.3895 & 0.0107 & 0.3895 & 0.0108 \\
\hline & -0.1 & & & 0.3564 & 0.001 & 0.3564 & 0.0008 \\
\hline & 0 & & & 0.3136 & & 0.3136 & \\
\hline & 0.5 & & & 0 & & 0.0000 & \\
\hline & 1 & & & 0.4191 & & -0.4191 & \\
\hline \multirow{6}{*}{0.2} & -0.3 & & & 0.3774 & 0.0307 & 0.3774 & 0.0319 \\
\hline & -0.2 & & & 0.3587 & 0.0099 & 0.3587 & 0.0099 \\
\hline & -0.1 & & & 0.3282 & 0 & 0.3282 & 0.0001 \\
\hline & 0 & & & 0.2888 & & 0.2888 & \\
\hline & 0.5 & & & 0 & & 0.0000 & \\
\hline & 1 & & & 0.3861 & & -0.3860 & \\
\hline
\end{tabular}

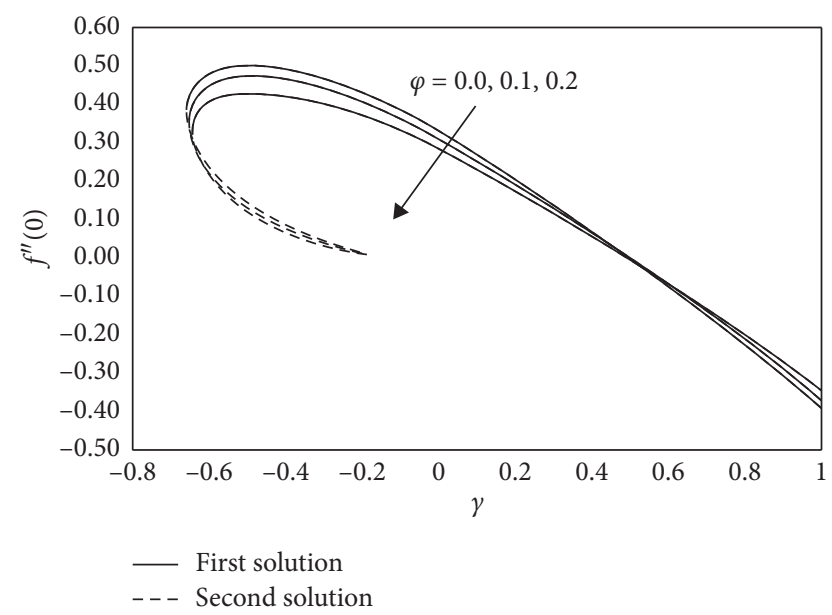

Figure 2: Distinction of $\varphi$ on $f^{\prime \prime}(0)$.

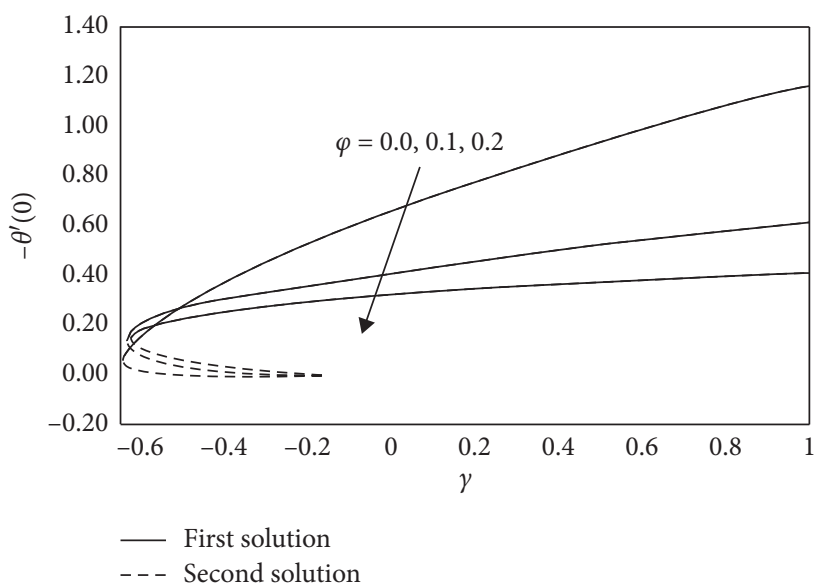

Figure 3: Distinction of $\varphi$ on $-\theta^{\prime}(0)$.

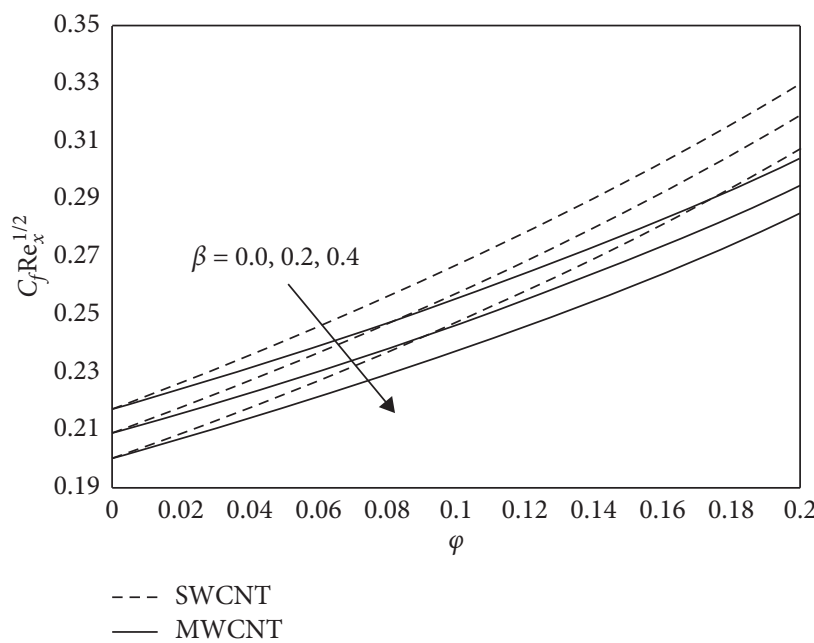

FIgURE 4: Distinction of $C_{f} \operatorname{Re}_{x}^{1 / 2}$ with $\varphi$ and $\beta$ for water-based nanofluid.

be seen quite evidently that an increase in the value of $N_{R}$ leads to a higher boundary layer thickness.

Further tests are conducted using the Anderson-Darling test statistics. The skin friction data (from Figure 2) are utilized to perform this test. The parameters, for each distribution that was tested, are displayed in Table 6. Table 7 shows the $\mathrm{AD}$ test statistics for the reduced skin friction data. Overall, the lowest $\mathrm{AD}$ values are obtained from the same distribution, i.e., the Weibull distribution. It implies that, as the volume fraction of nanoparticles increases, $\mathrm{AD}$ values still acknowledge that the Weibull distribution is the optimum one, among the other two distributions (gamma and exponential). Therefore, it can be concluded that the flow 


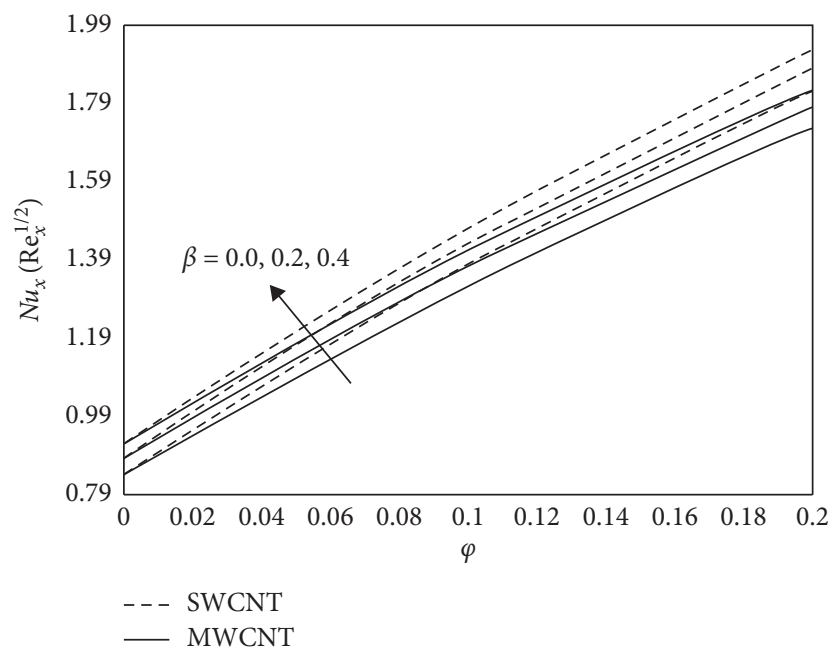

FIGURE 5: Distinction of $N u_{x} \operatorname{Re}_{x}^{-1 / 2}$ with $\varphi$ and $\beta$ for water-based nanofluid.

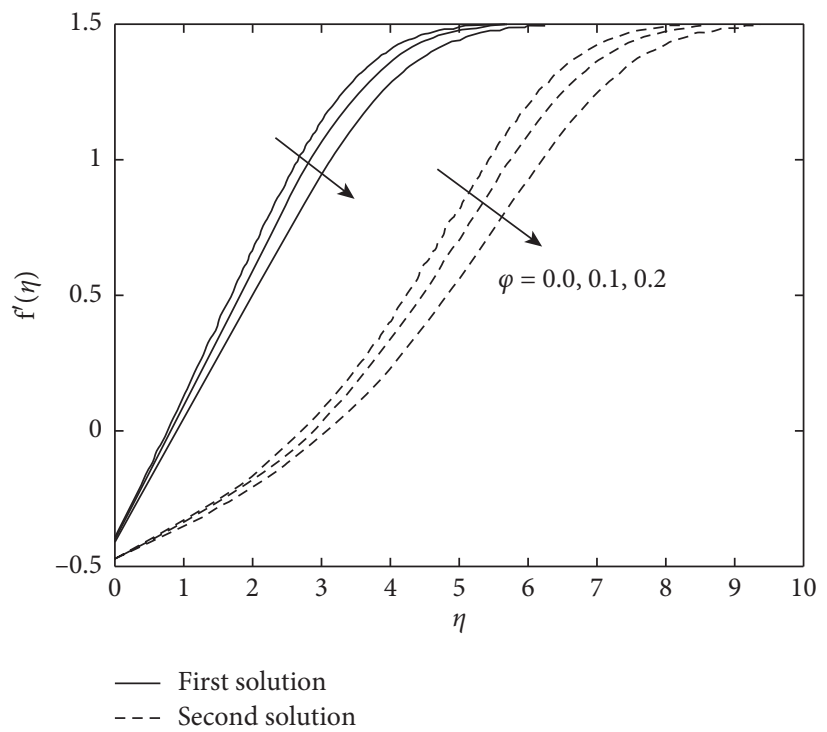

FIGURE 6: Effect of various values of $\varphi$ on the velocity profile for water-based SWCNTs.

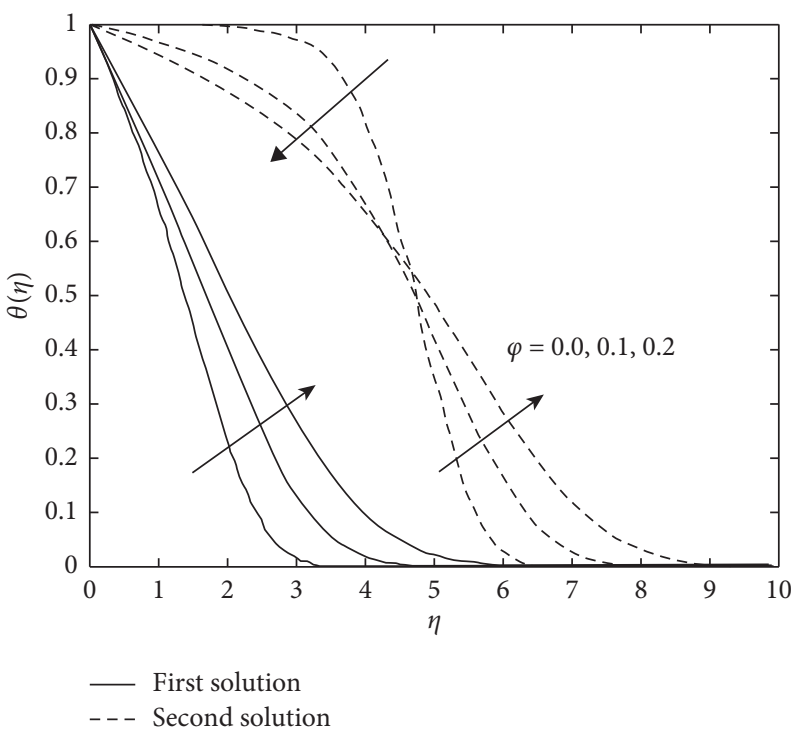

Figure 7: Effect of various values of $\varphi$ on the temperature profile for $\beta=0.2, \gamma=-0.5$, and NR $=0.1$. 


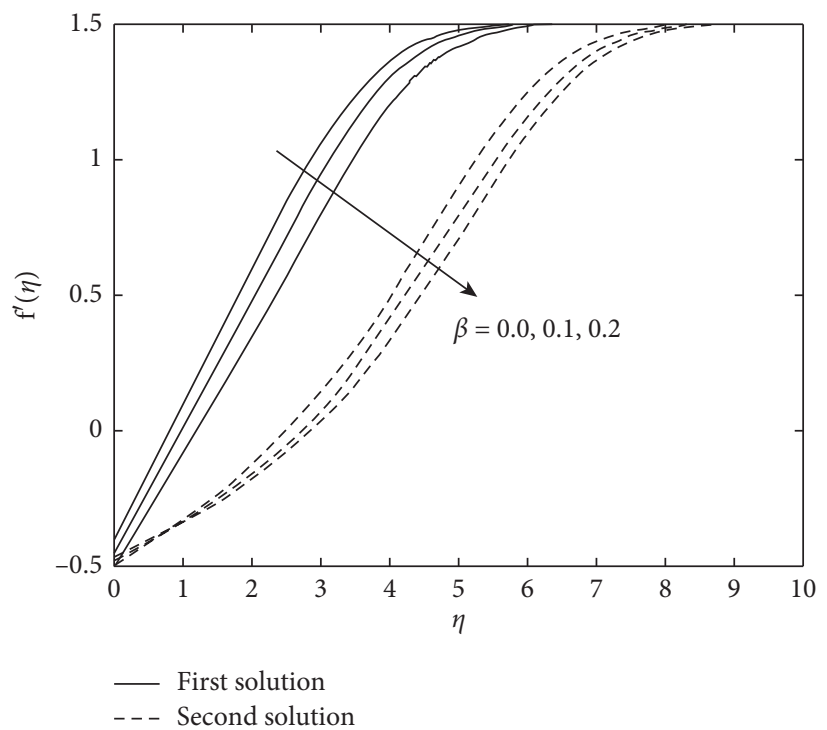

FIGURE 8: Effect of various values of $\beta$ on the velocity profile for water-based SWCNTs.

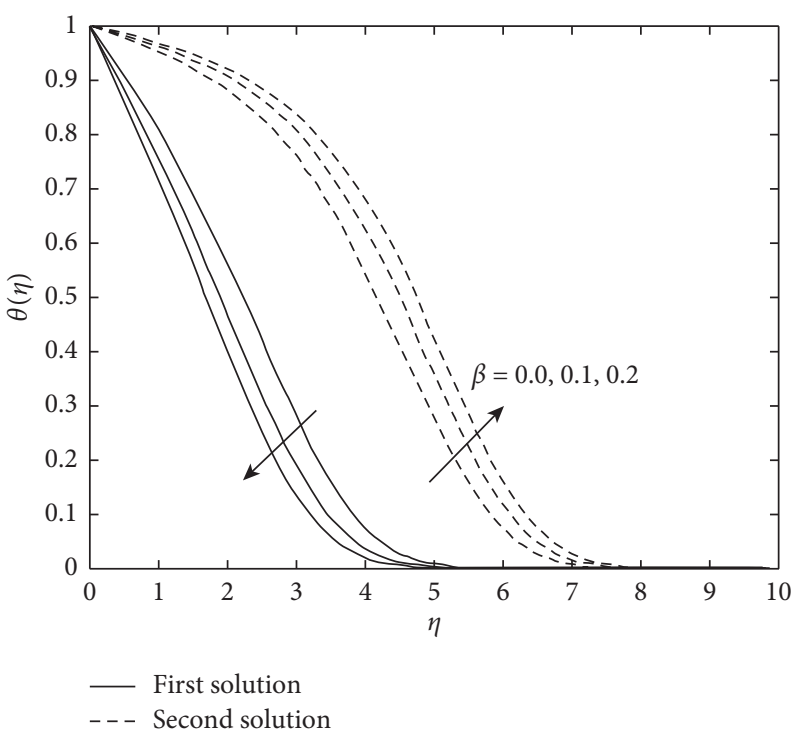

FIGURE 9: Effect of various values of $\beta$ on the temperature profile for water-based SWCNTs.

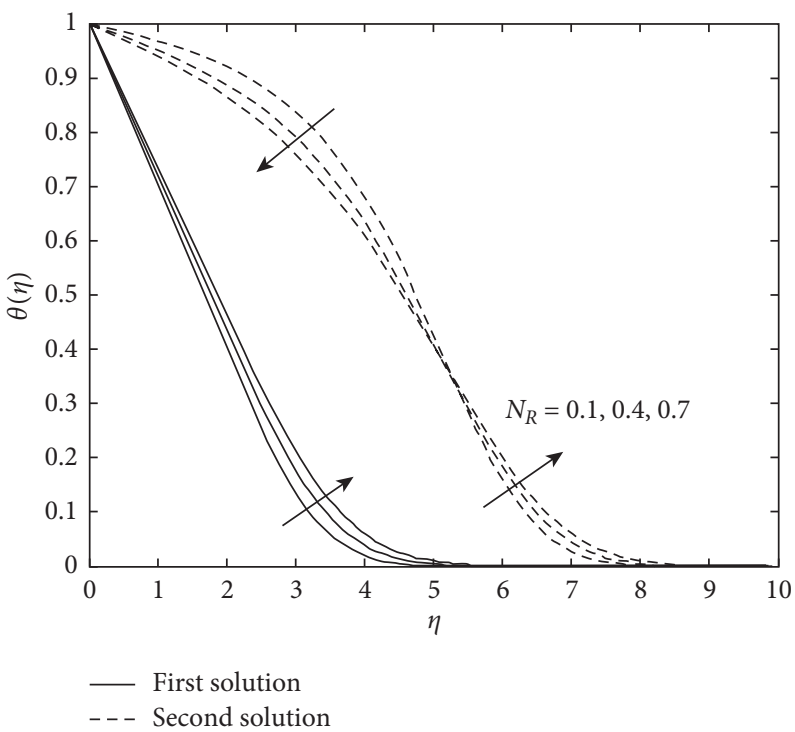

FIGURE 10: Effect of various values of thermal radiation on the temperature profile for water-based SWCNTs. 
TABLE 6: Parameters of statistical distributions for the water-based CNT.

\begin{tabular}{lcccc}
\hline & & & $\Phi$ & \\
& & 0 & 0.1 & 0.2 \\
\hline \multirow{2}{*}{ Weibull } & $\Delta$ & 0.36539 & 0.34854 & 0.31421 \\
& $\mathrm{~B}$ & 0.08672 & 0.08175 & 0.07506 \\
Gamma & $\mathrm{A}$ & 0.06947 & 0.06493 & 0.06017 \\
& $\mathrm{~B}$ & 4.53849 & 4.64135 & 4.50228 \\
Exponential & $\Theta$ & 0.31527 & 0.30135 & 0.27089 \\
\hline
\end{tabular}

TABLE 7: AD test for the reduced skin friction.

\begin{tabular}{lccc}
\hline & & $\Phi$ & \\
& 0 & 0.1 & 0.2 \\
\hline Weibull & 19.3557 & 19.75253 & 17.24832 \\
Gamma & 29.10256 & 31.18211 & 30.17244 \\
Exponential & 41.99866 & 46.03732 & 48.92685 \\
\hline
\end{tabular}

enhancement depends on low values of nanoparticle volume fraction and slip parameter. However, the higher thermal radiation will enhance the temperature at the boundary layer. The data of the Weibull distribution should concur with the data from different orders of slip; hence, it is very important to fit the data using statistical modelling.

\section{Conclusion}

In the present work, a detailed analysis of the influences of slip and thermal radiation of carbon nanotubes' (SWCNTs and MWCNTs) flow over a moving plate is conducted. From the analysis, an exact solution was found when the plate moves in the assisting flow condition, while dual solutions appeared in the opposing flow condition. It is also found that an increment in volume fraction of nanoparticles at $\varphi=0.2$ decreased the skin friction and heat transfer rate since it influences the boundary layer thickness. At $\beta=0.4$, the skin friction decreases, whereas the heat transfer rate increases. In contrast, as $N_{R}$ increases to 0.7 , the heat transfer rate decreases. In addition, for all other values of $\beta=0,0.2$, and 0.4 , it is found that the SWCNTs are more efficient, as compared with MWCNTs, with regard to the skin friction coefficient and the Nusselt number. Moreover, these results verified that the skin friction data fit the Weibull distribution, which are found to be in good agreement with results of the previous study [33]. The slip and thermal radiation are also modelled based on the flow and heat enhancement of CNTs. However, to explain the flow and heat enhancement of CNTs in studies on fluid dynamics, further research in the domain of slip is needed.

\section{Data Availability}

The data used to support the findings of this study are available from the corresponding author upon request.

\section{Conflicts of Interest}

The authors declare that they have no conflicts of interest.

\section{Acknowledgments}

This work was supported by Universiti Kebangsaan Malaysia (GGPM-2017-036).

\section{References}

[1] S. U. S. Choi and J. A. Eastman, Enhancing Thermal Conductivity of Fluids with Nanoparticles, American Society of Mechanical Engineers, New York, NY, USA, 1995.

[2] B. C. Pak and Y. I. Cho, "Hydrodynamic and heat transfer study of dispersed fluids with submicron metallic oxide particles," Experimental Heat Transfer, vol. 11, no. 2, pp. 151-170, 1998.

[3] A. H. A. Alwaeli, K. Sopian, K. Sopian, S. Mat, and M. H. Ruslan, "Concepts and challenges of nanofluids and phase change material (PCM) in photovoltaic thermal (PV/T) collectors: a review," Jurnal Kejuruteraan, vol. SI1, no. 3, pp. 31-36, 2018.

[4] H. Berrehal and A. Maougal, "Entropy generation analysis for multi-walled carbon nanotube (MWCNT) suspended nanofluid flow over wedge with thermal radiation and convective boundary condition," Journal of Mechanical Science and Technology, vol. 33, no. 1, pp. 459-464, 2019.

[5] A. Shafiq, I. Khan, G. Rasool, E. M. Sherif, and A. H. Sheikh, "Influence of single- and multi-wall carbon nanotubes on magnetohydrodynamic stagnation point nanofluid flow over variable thicker surface with concave and convex effects," Mathematics, vol. 8, no. 104, 2020.

[6] N. S. Anuar, N. Bachok, N. M. Arifin, and H. Rosali, "Role of multiple solutions in flow of nanofluids with carbon nanotubes over a vertical permeable moving plate," Alexandria Engineering Journal, vol. 59, no. 2, pp. 763-773, 2020.

[7] K. Naganthran, R. Nazar, and I. Pop, "Effects of heat generation/absorption in the Jeffery fluid past a permeable stretching/shrinking disc," Journal of the Brazilian Society of Mechanical Sciences and Engineering, vol. 41, pp. 1-12, 2019.

[8] S. Ahmad, M. Tarawneh, S. Y. Yahya, and R. Rasid, "Reinforced thermoplastic natural rubber (TPNR) composites with different types of carbon naotubes (MWNTS)," in Carbon NanotubesSynthesis, Characterization, Applications, S. Yellampalli, Ed., pp. 443-468, Open Access, London, UK, 2011.

[9] W. A. Khan, Z. H. Khan, and M. Rahi, "Fluid flow and heat transfer of carbon nanotubes along a flat plate with Navier slip boundary," Applied Nanoscience, vol. 4, no. 5, pp. 633-641, 2014.

[10] N. Anuar, N. Bachok, and I. Pop, "A stability analysis of solutions in boundary layer flow and heat transfer of carbon nanotubes over a moving plate with slip effect," Energies, vol. 11, no. 12, p. 3243, 2018.

[11] M. Bahiraei, "Particle migration in nanofluids: a critical review," International Journal of Thermal Sciences, vol. 109, pp. 90-113, 2016.

[12] M. Bahiraei and S. Heshmatian, "Graphene family nanofluids: a critical review and future research directions," Energy Conversion and Management, vol. 196, pp. 1222-1256, 2019.

[13] M. Bahiraei, R. Rahmani, A. Yaghoobi, E. Khodabandeh, R. Mashayekhi, and M. Amani, "Recent research contributions concerning use of nanofluids in heat exchangers: a critical review," Applied Thermal Engineering, vol. 133, pp. 137-159, 2018.

[14] M. Bahiraei and S. Heshmatian, "Electronics cooling with nanofluids: a critical review," Energy Conversion and Management, vol. 172, pp. 438-456, 2018. 
[15] M. H. Esfe, M. Afrand, W. Yan et al., "Effects of temperature and concentration on rheological behavior of MWCNTs/ $\mathrm{SiO}_{2}(20-80)-\mathrm{SAE} 40$ hybrid nano-lubricant," International Communications in Heat and Mass Transfer, vol. 76, pp. 133-138, 2016.

[16] M. H. Aghahadi, M. Niknejadi, and D. Toghraie, "An experimental study on the rheological behavior of hybrid Tungsten oxide $\left(\mathrm{WO}_{3}\right)$-MWCNTs/engine oil Newtonian nanofluids," Journal of Molecular Structure, vol. 1197, no. 5, pp. 497-507, 2019.

[17] M. Zadkhast, D. Toghraie, and A. Karimipour, "Developing a new correlation to estimate the thermal conductivity of MWCNT-CuO/water hybrid nanofluid via an experimental investigation," Journal of Thermal Analysis and Calorimetry, vol. 129, no. 2, pp. 859-867, 2017.

[18] M. H. Esfe, M. Afrand, S. H. Rostamian, and D. Toghraie, "Examination of rheological behavior of MWCNTs/ZnOSAE40 hybrid nano-lubricants under various temperatures and solid volume fractions," Experimental Thermal and Fluid Science, vol. 80, no. 1, pp. 384-390, 2016.

[19] A. Afshari, M. Akbari, and D. Toghraie, "Experimental investigation of rheological behavior of the hybrid nanofluid of MWCNT-alumina/water (80\%)-ethylene-glycol (20\%)," Journal of Thermal Analysis and Calorimetry, vol. 132, pp. 1001-1015, 2018.

[20] M. Goodarzi, D. Toghraie, M. Reiszadeh, and M. Afrand, "Experimental evaluation of dynamic viscosity of $\mathrm{ZnO}$ MWCNTs/engine oil hybrid nanolubricant based on changes in temperature and concentration," Journal of Thermal Analysis and Calorimetry, vol. 136, no. 2, pp. 513-525, 2019.

[21] A. A. A. A. Alrashed, O. A. Akbari, A. Heydari et al., "The numerical modeling of water/FMWCNT nanofluid flow and heat transfer in a backward-facing contracting channel," Physica B: Condensed Matter, vol. 537, pp. 176-183, 2018.

[22] A. Akhar and D. Toghraie, "An experimental study on the stability and thermal conductivity of water-ethylene glycol/ TiO2-MWCNTs hybrid nanofluid: developing a new correlation," Powder Technology, vol. 338, pp. 806-818, 2018.

[23] A. Arabpour, A. Karimipour, and D. Toghraie, "The study of heat transfer and laminar flow of kerosene/multi-walled carbon nanotubes (MWCNTs) nanofluid in the microchannel heat sink with slip boundary condition," Journal of Thermal Analysis and Calorimetry, vol. 131, no. 2, pp. 1553-1566, 2018.

[24] M. R. Gholami, O. A. Akbari, A. Marzban, D. Toghraie, G. A. S. Shabani, and M. Zarringhalam, "The effect of rib shape on the behavior of laminar flow of oil/MWCNT nanofluid in a rectangular microchannel," Journal of Thermal Analysis and Calorimetry, vol. 134, no. 3, pp. 1611-1628, 2018.

[25] K. Bhattacharyya, G. C. Layek, and R. S. R. Gorla, "Slip effect on boundary layer flow on a moving flat plate in a parallel free stream," International Journal of Fluid Mechanics Research, vol. 39, no. 5, pp. 438-447, 2012.

[26] N. Bachok, A. Ishak, R. Nazar, and N. Senu, "Stagnation-point flow over a permeable stretching/shringking sheet in a copper-water nanofluids," Boundary Value Problems, vol. 39, 2013.

[27] M. Imtiaz, T. Hayat, A. Alsaedi, and B. Ahmad, "Convective flow of carbon nanotubes between rotating stretchable disks with thermal radiation effects," International Journal of Heat and Mass Transfer, vol. 101, pp. 948-957, 2016.

[28] R. K. Tiwari and M. K. Das, "Heat transfer augmentation in a two-sided lid-driven differentially heated square cavity utilizing nanofluids," International Journal of Heat and Mass Transfer, vol. 50, no. 9-10, pp. 2002-2018, 2007.
[29] H. F. Oztop and E. Abu-Nada, "Numerical study of natural convection in partially heated rectangular enclosures filled with nanofluids," International Journal of Heat and Fluid Flow, vol. 29, no. 5, pp. 1326-1336, 2008.

[30] A. Jamaludin, K. Naganthran, R. Nazar, and I. Pop, "Thermal radiation and MHD effects in the mixed convection flow of $\mathrm{Fe}_{3} \mathrm{O}_{4}$-water ferrofluid towards a nonlinearly moving surface," Processes, vol. 8, no. 95, 2020.

[31] L. F. Shampine, I. Gladwell, and L. Shampine, Solving ODE with MATLAB, Cambridge University Press, Cambridge, UK, 2003.

[32] N. Bachok, A. Ishak, and I. Pop, "Flow and heat transfer characteristics on a moving plate in a nanofluid," International Journal of Heat and Mass Transfer, vol. 55, no. 4, pp. 642-648, 2012.

[33] A. Jedi, A. Shamsudeen, N. Razali et al., "Statistical modeling for nanofluid flow: a stretching sheet with thermophysical property data," Colloids Interfaces, vol. 4, no. 3, 2020. 